FEATURE

Charlotte Richards and Wayne Roberts Office for National Statistics

\title{
Regional Gross Disposable Household Income
}

R egional Gross Disposable Household Income (GDHI) is presented at the NUTS1, NUTS2 and NUTS3 levels. Box 1 outlines the methodology used to derive GDHI figures and Box 2 describes the NUTS regional classification in greater detail. GDHI for 1995, the year in which the time series using the current methodology starts, are compared with 2007 which is the latest year for which data are available.

\section{Regional (NUTS1) Data}

Total GDHI has been increasing in all NUTS1 regions at a similar rate between 2006 and 2007 (see Table 1). The highest

Table 1 growth rates were in London and Northern Ireland, both 3.0 per cent. The lowest growth rate was in the North East with 1.9 per cent.

The UK growth rate was 2.5 per cent, which has slowed from 3.8 per cent between 2005 and 2006. This is reflected across all regions, where comparative rates between 2006 and 2007 ranged from 0.9 to 2.1 percentage points lower than in the previous period. This is illustrated by the South East where growth decreased from 3.5 to 2.6 per cent and the North East where growth decreased from 4.0 to 1.9 per cent.

GDHI per head of population for the concludes with ONS future plans for regional economic data.
GDHI: by NUTS1 Region, 2007

\begin{tabular}{|c|c|c|c|c|c|}
\hline Region & $\begin{array}{l}\text { Total GDHI } \\
\text { (f million) }{ }^{1}\end{array}$ & $\begin{array}{r}\text { Share of } \\
\text { UK } \\
\text { (per cent) }{ }^{1}\end{array}$ & $\begin{array}{r}\text { Growth on } \\
2006 \\
\text { (per cent) }\end{array}$ & Per head $(\mathfrak{f})^{2}$ & $\begin{array}{r}\text { Per head } \\
\text { index } \\
(\mathrm{UK}=100)^{2} \\
\end{array}$ \\
\hline United Kingdom & 874,031 & 100.0 & 2.5 & 14,317 & 100 \\
\hline North East & 31,327 & 3.6 & 1.9 & 12,216 & 85 \\
\hline North West & 89,495 & 10.2 & 2.2 & 13,038 & 91 \\
\hline Yorkshire and the Humber & 66,789 & 7.6 & 2.6 & 12,901 & 90 \\
\hline East Midlands & 58,376 & 6.7 & 2.6 & 13,268 & 93 \\
\hline West Midlands & 69,646 & 8.0 & 2.2 & 12,941 & 90 \\
\hline East of England & 85,383 & 9.8 & 2.5 & 15,083 & 105 \\
\hline London & 135,502 & 15.5 & 3.0 & 17,931 & 125 \\
\hline South East & 133,724 & 15.3 & 2.6 & 16,095 & 112 \\
\hline South West & 73,462 & 8.4 & 2.6 & 14,187 & 99 \\
\hline England & 743,704 & 85.0 & 2.6 & 14,556 & 102 \\
\hline Wales & 37,470 & 4.3 & 2.2 & 12,574 & 88 \\
\hline Scotland & 69,895 & 8.0 & 2.3 & 13,587 & 95 \\
\hline Northern Ireland & 21,940 & 2.5 & 3.0 & 12,472 & 87 \\
\hline Extra-regio $^{3}$ & 1,023 & 0.1 & 1.9 & $\mathrm{n} / \mathrm{a}$ & $\mathrm{n} / \mathrm{a}$ \\
\hline
\end{tabular}

\section{Notes:}

Source: ONS Regional GDHI

1 Figures may not sum due to rounding.

$2 f$ per head and per head index exclude Extra-regio.

3 Parts of the UK economic territory that cannot be assigned to any particular region. 


\section{Box 1}

\section{Regional Gross Disposable Household Income: Definition and Methodology}

GDHI is the amount of money that individuals - the household sector - have available for spending or saving. This is money left after expenditure associated with income, for example, taxes and social contributions, property ownership and provision for future pension income. It is calculated gross of any deductions for capital consumption.

The household sector includes people living in traditional dwellings, as well as those living in institutions such as retirement homes and prisons. The sector includes sole trader enterprises and Non-Profit Institutions Serving Households (NPISHs), for example, most charities and universities.

\section{Derivation of Gross Disposable Household Income}

Total GDHI is derived from the balances of the primary and secondary income accounts.

Balance of the primary income account

+ Balance of the secondary income account

= Gross Disposable Household Income

\section{The Primary Income Account}

This account shows the income received by households for their role in the production process, also property income (rent on land, dividends and interest) received and paid. The largest component of UK GDHI is Compensation of Employees (CoE), which consists of wages and salaries and employers' social contributions.

The balance of primary income is the difference between total primary resources and uses.

$$
\begin{aligned}
& \text { Total primary resources } \\
\text { - } & \text { Total primary uses } \\
= & \text { Balance of primary income }
\end{aligned}
$$

Primary resources consist of COE (wages and salaries); operating surplus (mainly rental, imputed or otherwise, in the household sector); mixed income (income from self-employment); and property income receipts.

Primary uses are equivalent to property income paid.

\section{The Secondary Distribution of Income Account}

This account shows how the balance of primary income of households is modified by redistribution of payments of current taxes; payments of social contributions and receipts of benefits (other than in kind); and net other current transfers.

The balance of secondary income is derived as the difference of total secondary resources less uses.

Total secondary resources

- Total secondary uses

= Balance of secondary income

Secondary resources consist of social benefits and contributions received (including pension payments) and other current transfers received (for example, financial gifts and non-life insurance claims).

Secondary uses consist of current taxes on income and wealth (mainly income tax and council tax), social contributions paid (employees pension and social security contributions) and other current transfers paid (financial gifts, charitable donations and non-life insurance premia).

\section{GDHI publication and production}

Regional GDHI estimates are published annually for the period 1995 to T-2 years (T being the year of publication) and are consistent with the National Accounts Blue Book. Component estimates are published at the NUTS2 sub-regional area and the balances of primary and secondary incomes are published for the NUTS3 local areas. This breakdown is required by Eurostat (the Statistical Office of the European Union).

The estimate of total national GDHI is allocated to regions using a variety of regional indicators. Regional GDHI estimates are initially produced at NUTS3 level and aggregated up to obtain NUTS2 and NUTS1 estimates. These estimates are made on a residence basis; in other words incomes of individuals are allocated to the region in which they live rather than where they work. The data referenced in this article are calculated using a five-year end-point moving average. These adjusted figures remove some year-on-year volatility caused by sampling and non-sampling errors in the data sources. Estimates to which this process has been applied are referred to as 'headline' estimates. The unadjusted 'raw' data are also published by ONS and are supplied to Eurostat.

Regional GDHI estimates are produced at current basic prices, so the effects of inflation are not taken into account in these data.

\section{Data Sources}

The national data are allocated to the regional level using the most appropriate indicators available and are drawn from a wide variety of survey and administrative sources. The main datasets used to calculate regional GDHI are:

- HM Revenue \& Customs (HMRC) Pay-As-You-Earn (PAYE)

- HMRC wages and salaries

- HMRC self-assessment tax and Survey of Personal Incomes (SPI)

- Other HMRC taxes data

- Various benefit datasets.

Data from these datasets are used as indicators to apportion the National Accounts household accounts components. The methods used are consistent with the guidance set out in the European System of Accounts 1995 (ESA95).

All the input data are subject to a rigorous quality assurance process to ensure that they are the best indicators available. 


\section{Box 2}

\section{Regional Classification}

The Nomenclature of Units for Territorial Statistics (NUTS) provides a uniform breakdown for the production of regional statistics for the European Union. Regional GDHI estimates are produced at three levels of NUTS in the UK. These are:

- NUTS1: the devolved administrations of Scotland, Wales and Northern Ireland and the Government Office Regions (GORs) of England
- NUTS2: 37 sub-regions - sometimes referred to as groups of counties

- NUTS3: 133 areas - generally groups of unitary authorities or districts, also known as local areas

- Extra-regio GDHI is that which cannot be assigned to any region, such as the GDHI of embassies and UK armed forces stationed overseas. It also pertains to elements of activities on the continental shelf such as oil and gas extraction.

\section{Figure 1}

\section{Share of UK GDHI: by NUTS1 Region, 2007}

Percentages

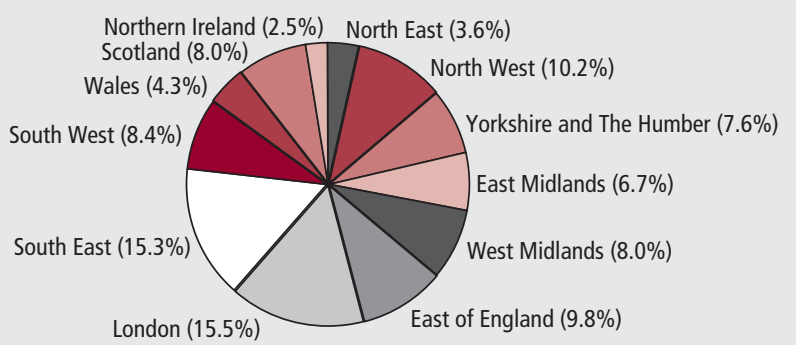

Source: ONS Regional GDHI

\section{Figure 2}

\section{GDHI per head indices: by NUTS1 Region}

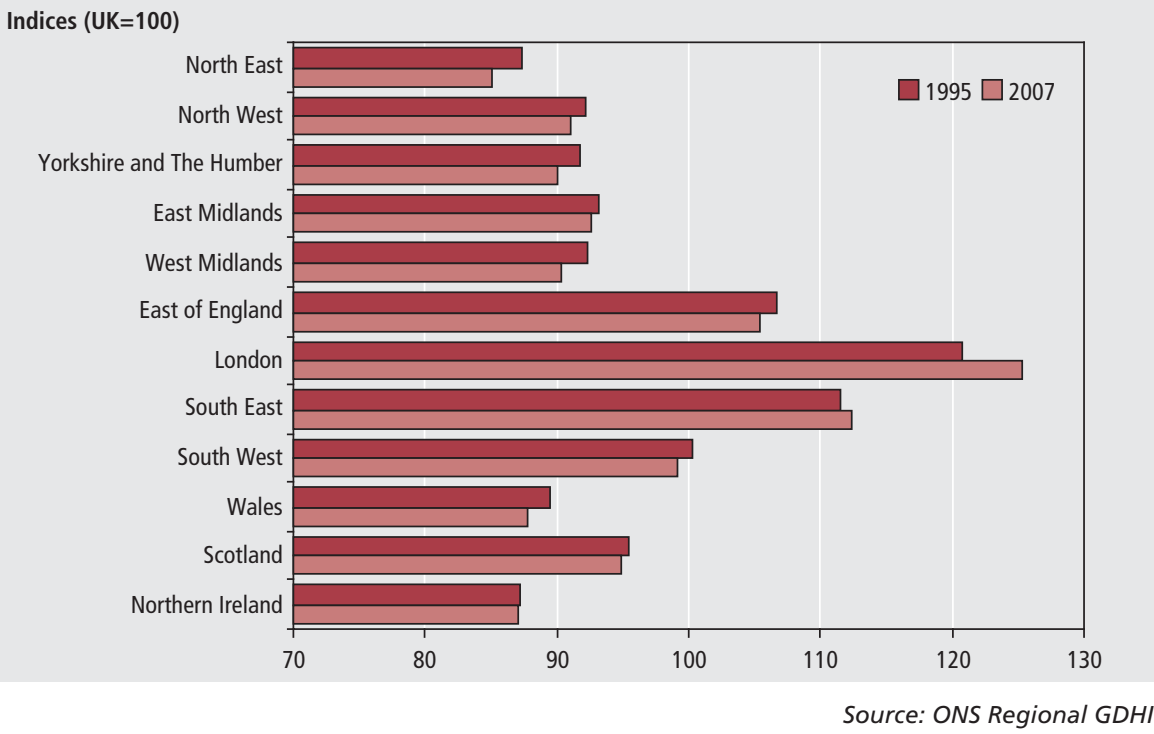

UK as a whole, excluding Extra-regio, was $£ 14,317$ in 2007. London had the highest GDHI per head of $£ 17,931$. The South East and East of England were also above the UK average at $£ 16,095$ and $£ 15,083$ respectively. All other regions had a GDHI per head below the UK average. The North East and Northern Ireland had the lowest GDHI per head, with $£ 12,216$ and $£ 12,472$ respectively (see Map 1).

Figure 1 shows that London (15.5 per cent) and the South East (15.3 per cent) had the largest shares of total GDHI in 2007, while Northern Ireland (2.5 per cent) and
North East (3.6 per cent) had the smallest shares.

Figure 2 shows that London had the highest regional GDHI per head of population index in 2007 , which was 25 points greater than the UK average and four points above the corresponding 1995 index. The North East and Northern Ireland had the lowest indices, 15 and 13 index points below the UK average respectively. Between 1995 and 2007, London and the South East were the only regions where per head indices rose. All the other NUTS1 regions' per head indices were either the same between 1995 and 2007 or fell within this time period.

\section{Sub-Regional (NUTS2) Data}

Within the 37 sub-regions (mainly groups of counties) of the UK, Inner London had the highest household income per head of $£ 20,163$ in 2007, while the West Midlands had the lowest household income per head of $£ 11,731$ (see Table 2).

In 2007,14 of the 37 sub-regions were above the UK household income per head (see Map 2), including all those within London and South East. All sub-regions within the East Midlands, North East, Wales and Northern Ireland were below the UK average.

Figures 3 and 4 compare the top five and bottom five ranked sub-regions in 2007 and 1995. There was no change in the top five sub-regional rankings. In 1995, Highlands and Islands and Northern Ireland were within the bottom five sub-regional rankings; by 2007 they had been replaced by Tees Valley and Durham and West Wales and the Valleys. The largest movement of a GDHI per head index between 1995 and 2007 was in Inner London, rising from 130 to 141.

\section{Local Area (NUTS3) Data}

The NUTS3 local areas with the highest GDHI per head in 2007 were Inner London - West with $£ 27,838$, Surrey $£ 20,019$, Buckinghamshire CC $£ 19,458$, Hertfordshire $£ 17,869$ and Outer London - West and North West $£ 17,726$. Of the 133 NUTS3 areas, 42 were above the UK average of $£ 14,317$. Nottingham with $£ 10,336$, City of Kingston upon Hull $£ 10,495$, Blackburn with Darwen $£ 10,793$, Leicester $£ 10,855$ and Stoke-on-Trent $£ 11,167$ were the NUTS3 areas with the lowest GDHI per head in 2007 (see Table 3).

Figures 5 and $\mathbf{6}$ compare the top five and bottom five ranked NUTS3 local areas in 2007 and 1995. The top five had only one minor change when comparing 1995 and 2007, with Outer London South being fifth in 1995 and Outer London - West and North West replacing it in 2007. Within 
Table 2

Top five and bottom five GDHI per head: by NUTS2 Sub-Regions, 2007

\begin{tabular}{|c|c|c|c|c|}
\hline Region & Per head $(\mathrm{f})^{1}$ & $\begin{array}{r}\text { Per head } \\
\text { index } \\
(\mathrm{UK}=100)^{1}\end{array}$ & $\begin{array}{l}\text { Total GDHI } \\
\text { (f million) }{ }^{1}\end{array}$ & $\begin{array}{r}\text { Share of UK } \\
\text { (per cent) }\end{array}$ \\
\hline United Kingdom ${ }^{1}$ & 14,317 & 100 & 874,031 & 100.0 \\
\hline \multicolumn{5}{|l|}{ Top five GDHI per head } \\
\hline Inner London & 20,163 & 141 & 60,495 & 6.9 \\
\hline Surrey, East and West Sussex & 17,444 & 122 & 45,987 & 5.3 \\
\hline Berkshire, Buckinghamshire and Oxfordshire & 16,988 & 119 & 37,038 & 4.2 \\
\hline Bedfordshire and Hertfordshire & 16,539 & 116 & 27,486 & 3.1 \\
\hline Outer London & 16,461 & 115 & 75,007 & 8.6 \\
\hline \multicolumn{5}{|l|}{ Bottom five GDHI per head } \\
\hline Northumberland and Tyne and Wear & 12,413 & 87 & 17,387 & 2.0 \\
\hline South Yorkshire & 12,323 & 86 & 16,013 & 1.8 \\
\hline West Wales and the Valleys & 12,265 & 86 & 23,206 & 2.7 \\
\hline Tees Valley and Durham & 11,978 & 84 & 13,949 & 1.6 \\
\hline West Midlands & 11,731 & 82 & 30,547 & 3.5 \\
\hline
\end{tabular}

Notes:

Source: ONS Regional GDHI

$1 \mathrm{f}$ per head and per head index exclude Extra-regio, while the total $\mathrm{fm}$ for the UK includes Extra-regio.

\section{Figure 3 \\ Top and bottom five GDHI per head indices: by NUTS2 Sub-Region, 2007}

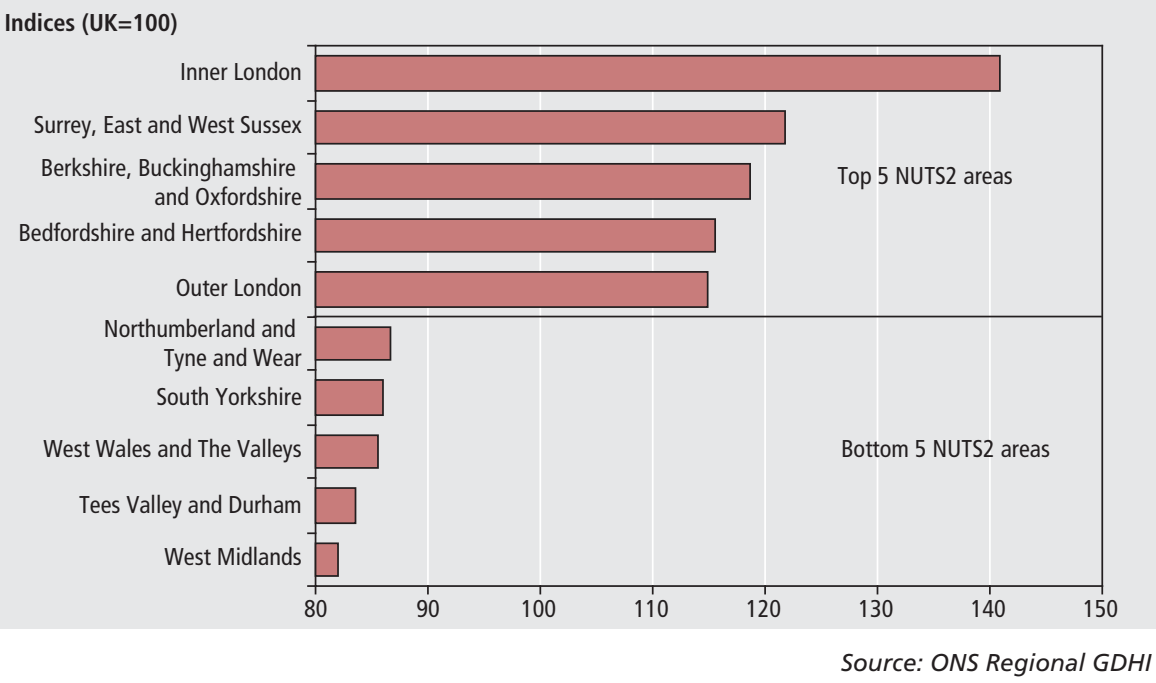

Figure 4

Top and bottom five GDHI per head indices: by NUTS2 Sub-Region, 1995

Indices $(\mathrm{UK}=100)$

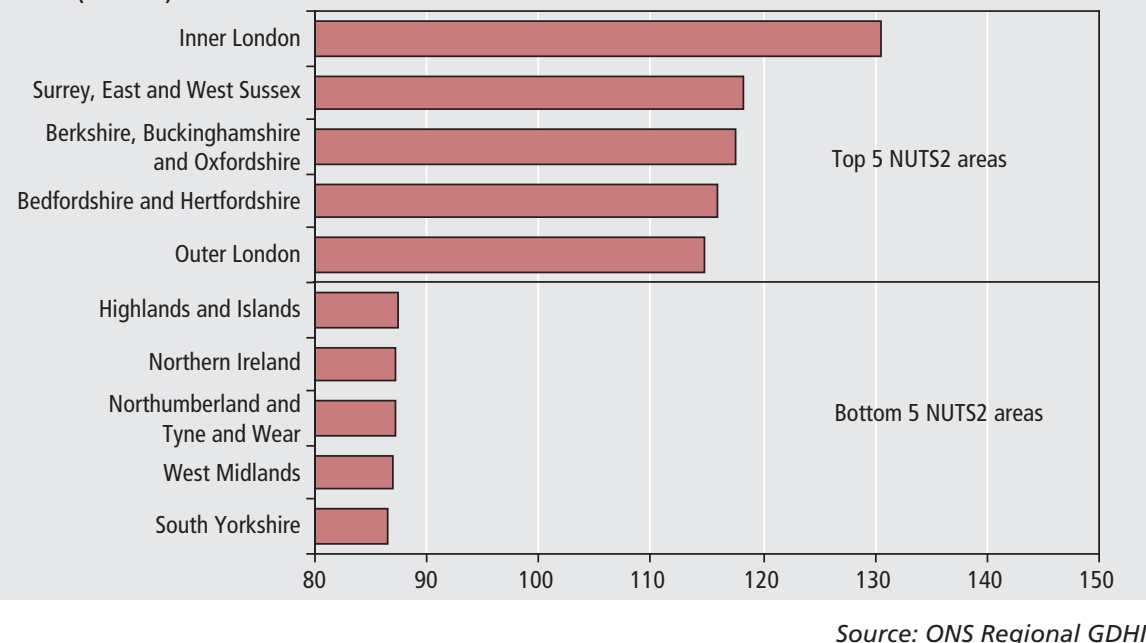

the bottom five ranked local areas, only City of Kingston upon Hull remained. Stoke-on-Trent, Leicester, Blackburn with Darwen and Nottingham all moved into the bottom five in 2007. The largest movement of household per head indices between 1995 and 2007 was in Inner London - West increasing from 180 in 1995 to 194 in 2007.

\section{Composition of Households}

Figure 7 illustrates the composition of household income in West Midlands and Inner London, the NUTS2 sub-regions with the lowest and highest GDHI per head respectively. These are in comparison to the 2007 UK average.

The West Midlands GDHI per head value in 2007 was 18 per cent below the UK average. This was driven mainly by the contribution of $\mathrm{CoE}$ to its total income, which was 20 per cent below the UK average. In comparison, Inner London's CoE per head was 69 per cent above the UK average of $£ 12,205$.

Income from Gross Operating Surplus (GOS) and Mixed Income (MI) was also above average in Inner London at $£ 4,323$ per head, 61 per cent above the UK average. In West Midlands conversely, income from GOS and MI accounted for $£ 1,904$ per head in 2007, 29 per cent below the UK average of $£ 2,681$.

In West Midlands all components were lower than their UK average counterparts. Conversely for Inner London, all components, with the exception of Other Current Transfers (OCT) Uses and Social Benefits, were above average.

\section{Social Benefits}

Social benefits are the main component of secondary resources, i.e. income for households following re-distribution. In 
Table 3

Top five and bottom five GDHI per head: by NUTS3 local areas, 2007

\begin{tabular}{|c|c|c|c|}
\hline Region & Per head $(\mathrm{f})^{1}$ & Per head index $(\mathrm{UK}=100)^{1}$ & $\begin{array}{l}\text { Total GDHI } \\
\text { (f million) }^{1}\end{array}$ \\
\hline United Kingdom ${ }^{1}$ & 14,317 & 100 & 874,031 \\
\hline \multicolumn{4}{|l|}{ Top five GDHI per head } \\
\hline Inner London - West & 27,838 & 194 & 30,818 \\
\hline Surrey & 20,019 & 140 & 21,986 \\
\hline Buckinghamshire CC & 19,458 & 136 & 9,546 \\
\hline Hertfordshire & 17,869 & 125 & 19,050 \\
\hline Outer London - West and North West & 17,726 & 124 & 31,390 \\
\hline \multicolumn{4}{|l|}{ Bottom five GDHI per head } \\
\hline Stoke-on-Trent & 11,167 & 78 & 2,669 \\
\hline Leicester & 10,855 & 76 & 3,176 \\
\hline Blackburn with Darwen & 10,793 & 75 & 1,520 \\
\hline Kingston upon Hull, City of & 10,495 & 73 & 2,697 \\
\hline Nottingham & 10,336 & 72 & 2,984 \\
\hline
\end{tabular}

\section{Notes:}

Source: ONS Regional GDHI

$1 \mathrm{f}$ per head and per head index exclude Extra-regio, while the total $\mathrm{fm}$ for the UK includes Extra-regio.

\section{Figure 5 \\ Top and bottom five GDHI per head indices: by NUTS3 local areas, 2007}

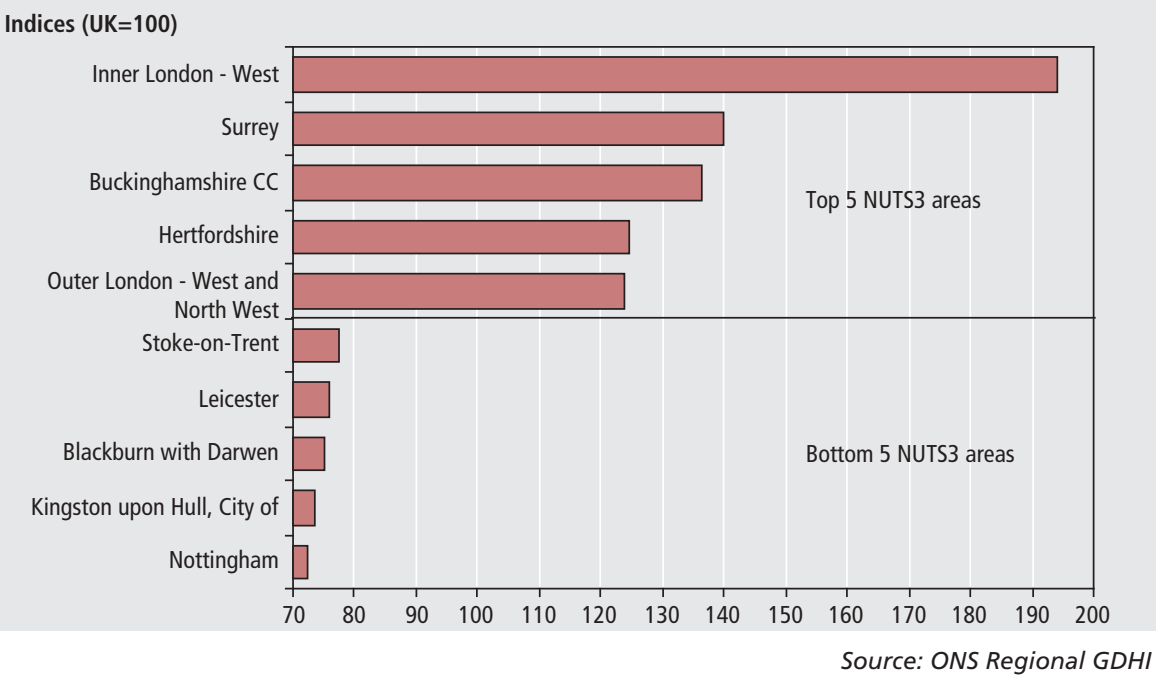

Figure 6

Top and bottom five GDHI per head indices: by NUTS3 local areas, 1995

Indices $(\mathrm{UK}=100)$

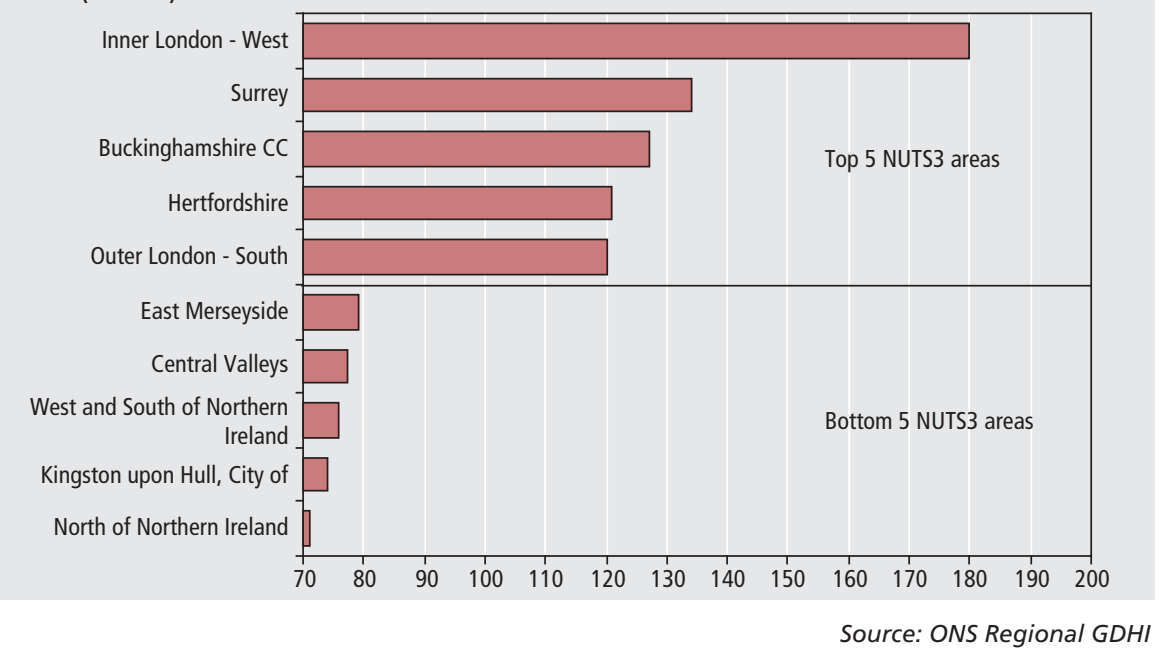

2007 social benefits worth about $£ 226$

billion were distributed nationally.

Most NUTS2 sub-regions follow the UK average relatively closely. Dorset and Somerset; Surrey, East and West Sussex; West Wales and the Valleys; Merseyside and Cumbria NUTS2 sub-regions received the highest level of social benefits (mainly from private pensions) per head in 2007 (see Figure 8). These sub-regions ranged from 12 to 15 per cent above the UK average figure of $£ 3,720$ per head.

Figure 8 also shows that Leicestershire, Rutland and Northamptonshire and North Eastern Scotland received the lowest social benefits at $£ 3,228$ and $£ 3,292$ respectively, 13 and 12 per cent below the UK average.

\section{Revisions}

The GDHI estimates published in April 2009 include some revisions to earlier published estimates for the period 1995 to 2006.

The main reasons for revisions are:

- revisions to the national data in UK National Accounts (Blue Book 2008), which go back to 2004 replacing provisional estimates with actual data

- further changes due to replacing estimates with actual data and methodological improvements

\section{Future Work Plans}

ONS plans to publish regional GVA for 1989 to 2008 at the NUTS1 level and 1995 to 2007 for NUTS2 and NUTS3 in December 2009. These data will be consistent with the National Accounts Blue Book 2009.

It is also planned to publish regional GDHI estimates at the NUTS1, 2 and 3 levels from 1995 to 2008 (consistent with the National Accounts Blue Book 2009) in Spring 2010. 


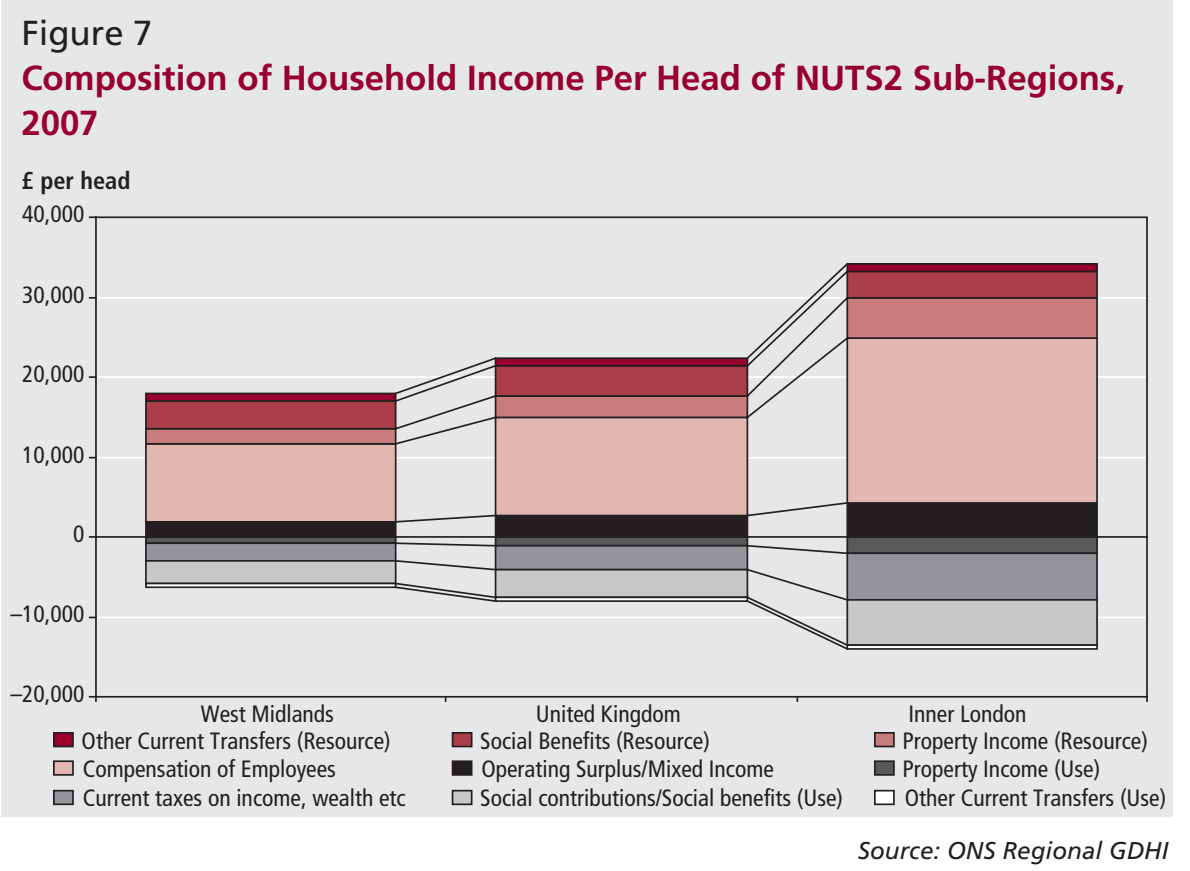

\section{Figure 8}

\section{NUTS2 Top and Bottom 5 Social Benefits (Resources) Per Head, 2007}

f per head

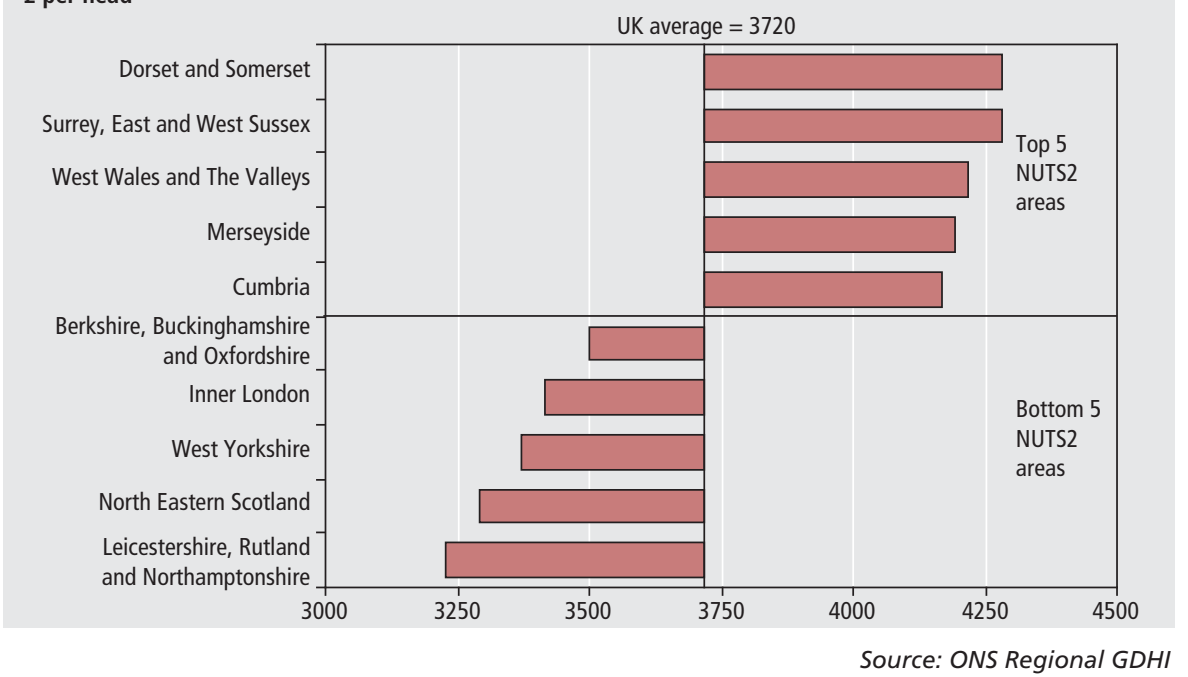

The ONS is currently developing experimental constant price estimates of GVA at the NUTS1 level based on the 'production' approach, to supplement the existing current price estimates based on the 'income' approach.

\section{Notes}

1. The full Regional Accounts Gross Disposable Household Income publication can be accessed on the National Statistics website at www.statistics.gov.uk/statbase/product. asp?vlnk=14651

2. The full Regional Accounts Gross Value Added publication can be accessed on the National Statistics website at www.statistics.gov.uk/statbase/product. asp?vlnk=14650

\section{CONTACT}

凶 elmr@ons.gsi.gov.uk

\section{REFERENCES}

Holmes E (2008) 'Regional Gross Disposable Household Income', Economic \& Labour Market Review 2 (8) pp 32- 40.

Humphries S (2008) 'Modernisation of the UK's National Accounts: progress and plans for Blue Book and Pink Book 2008', Economic \& Labour Market Review 2(6) pp 30-2.

Marais J (2007) 'Regional Household Income' www.statistics.gov.uk/cci/ article. asp?id $=1763$

Office for National Statistics (1998) National Accounts Concepts Sources and Methods, The Stationery Office: London.
Office for National Statistics (1998) Introducing the European System of Accounts 1995, The Stationery Office: London.

Office for National Statistics (2002) UK Standard Industrial Classification of Economic Activities 2003, The Stationery Office: London.

Office for National Statistics (2007) UK National Accounts Blue Book.

Office for the Official Publications of the European Communities (1996) European System of Accounts 1995, Eurostat.

White J (2009) 'Regional Gross Value Added', Economic \& Labour Market Review 3 (5) pp 42-54. 


\section{APPENDIX}

\section{Map 1}

Gross Disposable Household Income per head: by NUTS1 area, 2007

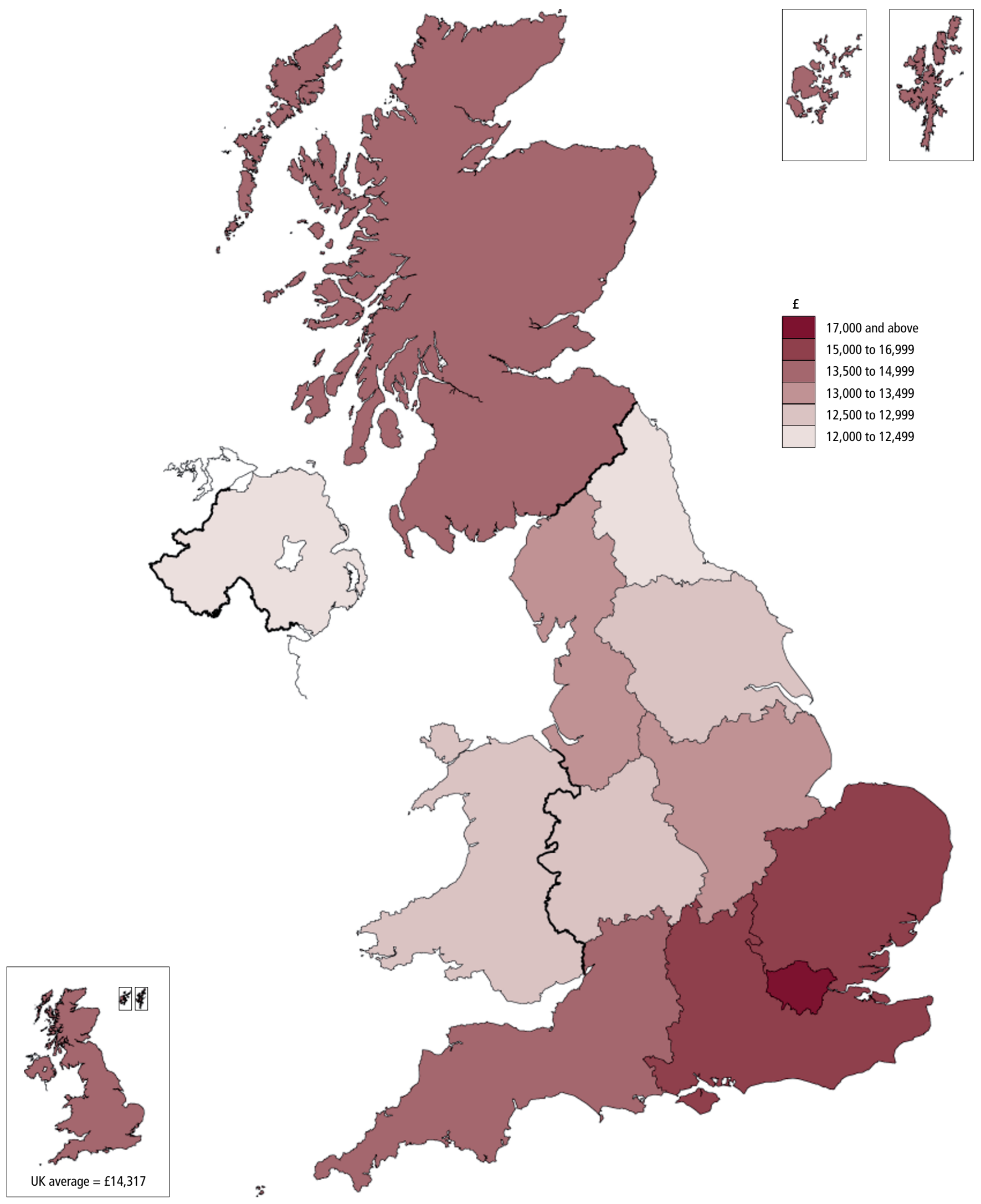




\section{Map 2}

Gross Disposable Household Income per head: by NUTS2 sub-region, 2007

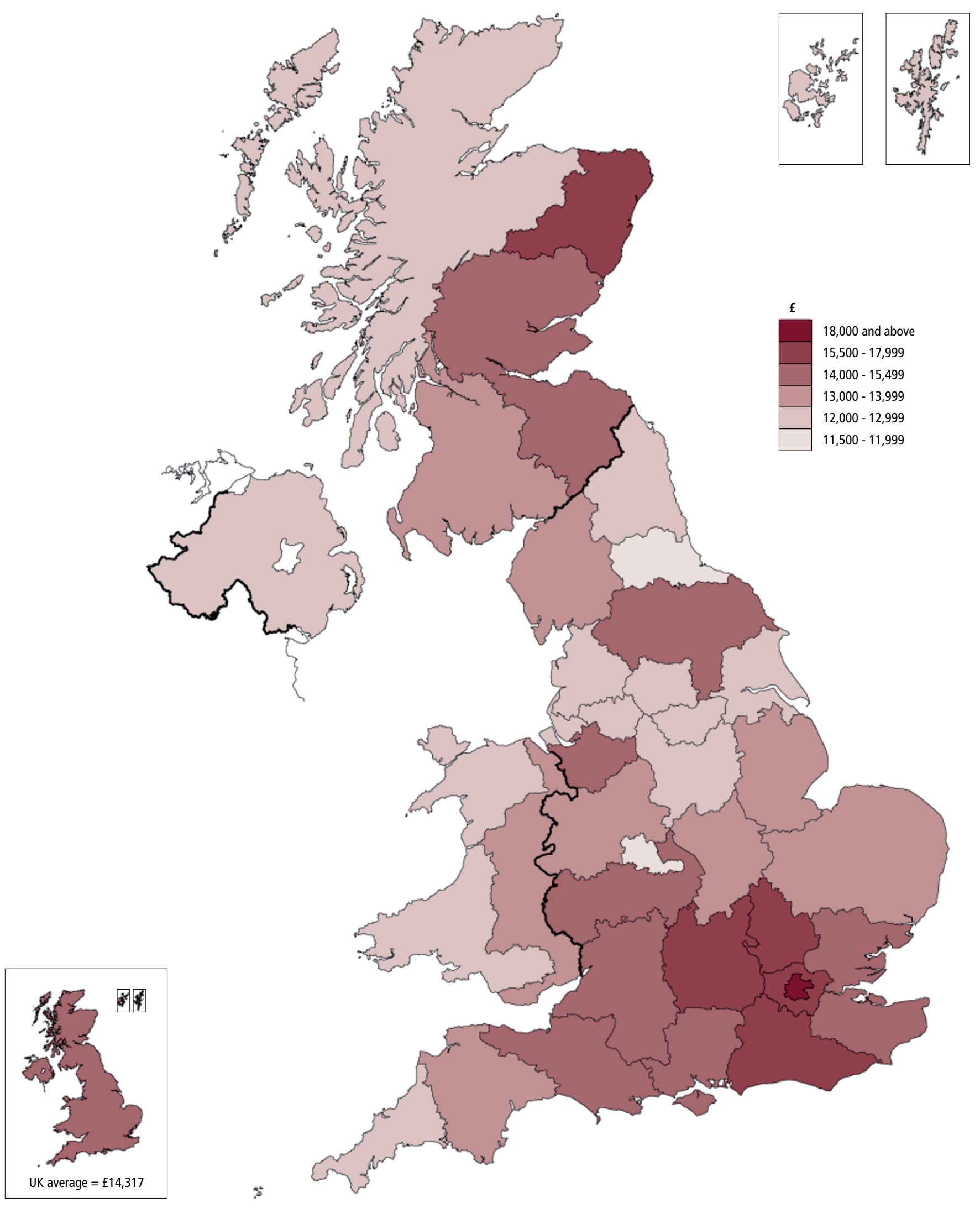




\section{Map 3}

Gross Disposable Household Income per head: by NUTS3 local area, 2007

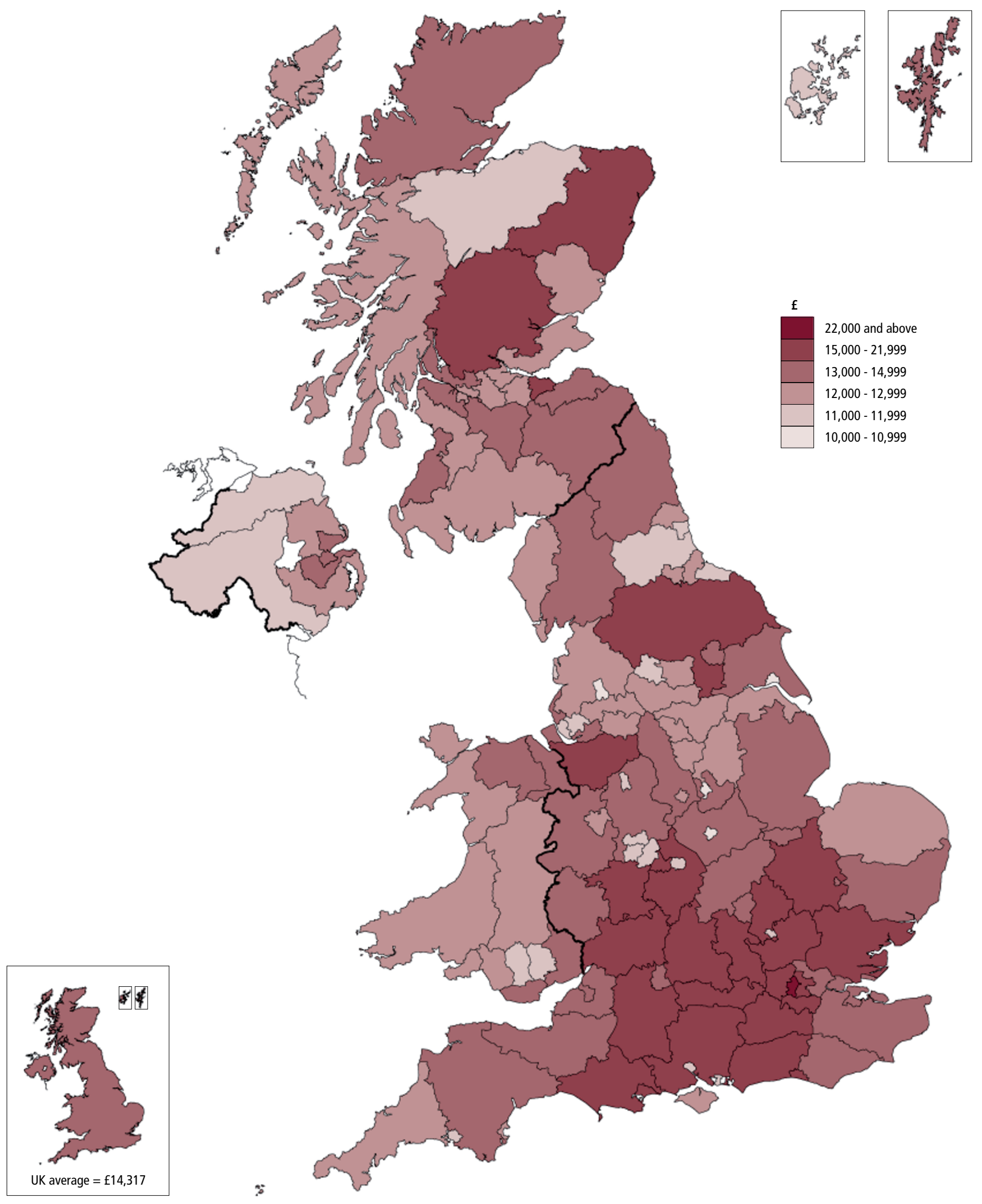

